\title{
Research on the Interest Rate Risk Management of Commercial Banks in China under Interest Rate Liberalization
}

\author{
Xiaokang Sheng \\ School of Finance, Nanjing University of Finance \& Economics \\ P. R. China, 210023
}

\begin{abstract}
As the liberalization of interest rate is basically completed, interest rate risk becomes a major risk of commercial banks. Based on the interest rate risk management model, this paper combines interest rate theory with practice and uses GAP model and GARCH model to analyze the interest rate risk management. Empirical evidence shows that commercial banks in China have actively managed short-term GAP values in the face of interest rate risks. Meanwhile, the yield sequence has the characteristic of long-term memory. Finally, this paper puts forward reasonable suggestions for commercial banks from five aspects.
\end{abstract}

Keywords-China; Interest rate risk management; Interest rate liberalization; Commercial banks

\section{INTRODUCTION}

In October 2015, the People's Bank of China (PBOC) lifted the ceiling on the floating deposit rate of commercial banks and rural cooperative financial institutions, which meant that the process of China's interest rate liberalization was coming to the end. As the main microeconomic subject in the financial market, interest rate liberalization makes commercial banks impacted inevitably. Meanwhile, interest rate risk is becoming the main risk for commercial banks after credit risk in China.

Driven by the financial liberalization, interest rate liberalization is first introduced in western countries. McKinnon and Shaw (1973) study the characteristics of developing countries' financial systems for the first time and put forward the theory of financial repression and deepening. They argue that developing countries have more serious financial repression phenomena, and suggest that developing countries should relax interest rate controls and use market to allocate resources much more to improve the efficiency of allocation and to promote the economic growth. Tressel (2009) introduces two virtual variables in his model--market interest rates and systematic risk of commercial banks to make an empirical analysis of the main variable in the economic development. The results show that the marketization of interest rate will have a negative effect on commercial banks, but it can also promote the economic growth. Dan Armeanu (2008) analyzes the interest rate risk by using duration gap model, and it turns out that the interest rate risk exposes commercial banks to the possibility of a great loss, so commercial banks should respond to it actively.
Many Chinese scholars have also studied in this area. Huang Jinlao (2001) believes that there are two kinds of risks in the process of interest rate liberalization: periodic risk and permanent risk. Shao Fujun (2004) analyzes the risk of interest rate liberalization from both micro and macro level. He holds the view that after the completion of interest rate liberalization, there will be far more frequent fluctuations in interest rates. Xiao Xinrong and Wu Yonggang (2011) study the influence of interest rate liberalization on commercial banks from three perspectives: assets and liabilities, intermediary business and industry concentration. Their research shows that when interest rate marketization is actually completed, the deposit and loan spreads will reduce and the diversification of financial products will increase rapidly. Jin Lingling, Ba Shusong (2012) find that after the completion of interest rate liberalization, the proportion of borrowed funds of commercial banks will gradually increase.

\section{INTEREST RATE LIBERALIZATION AND ITS RISKS}

Interest rate marketization refers to the interest rate determined by capital supply and demand in the market directly, and then an interest rate system is formed, in which the interest rates are centered by the benchmark rate, monetary policy is regarded as conduction intermediary, and the deposit and lending rates are decided by financial institutions in the market.

In the financial market, fund demanders and suppliers are stakeholders of the money capital, so they should have the right to determine the price of the fund. Interest rate liberalization makes the financial institutions involved in market transactions have the right to determine the level of deposit and loan interest rates independently, but the process of bargaining needs to have a wind indicator. Experience has shown that the volume of Treasury bills and interbank lending capital is very large, and has much more transparent information disclosed, so it can reflect the funds demand and supply of the whole financial market and can serve as a bellwether.

The spontaneous behavior of each market subject forms the term and risk structure of interest rate. Compared with the time limit and risk structure set by the authority, the term and risk structure chosen by the market are more closely related to the actual situation. Furthermore, interest rate liberalization does not preclude central banks or governments from using indirect means to influence interest rates, such as open market 
operations by the central bank to achieve the purpose of rate intervention.

Interest rate risk is the risk of loss of the overall interest and economic value of the economic subjects due to the adverse change of the interest rate level and term structure. Because of the differences in the source of risk, the interest rate risk can be divided into repricing risk, yield curve risk, option risk and benchmark risk. The repricing risk arises from the mismatch between the time of repricing and the maturity of the position in the balance sheet and the off-balance sheet, which is the most important form of interest rate risk. The uncertainty of the loss of the net income of banks due to the sudden shift of the yield curve or the unexpected change of slope is the risk of yield curve. The benchmark risk refers to the risk that the inconsistent adjustment of deposit and loan interest rates when the change of interest rate of different kinds of financial instruments varies in different degrees. Option risk is the probability that the interest rate will be changed at the time that clients are exercising the implied option (such as returning the loan principal and interest and withdrawing the deposit before maturity) to the bank.

It is worth noting that, in addition to the four risks mentioned above, banks face other risks derived from them, which mainly include the frustration risk of the reform of commercial banks for the purpose of effective management and operation, the risk coming from the shift of regulatory paradigms when commercial banks change their business type and restruct assets and liabilities, and etc.

\section{INTEREST RATE RISK MEASUREMENT METHODS OF COMMERCIAL BANKS}

As mentioned above, interest rate liberalization exposes banks to high interest rate risks, so commercial banks should identify and measure interest rate risks effectively with a positive attitude.

\section{A. Analysis of interest rate sensitive gap}

Interest rate sensitive gap analysis is based on risk managers' analysis of interest rate changing trend, and the sensitivity of capital allocation is timely adjusted in order to realize net interest income or profit maximization. Funding gap is the difference between interest rate sensitive assets and liabilities: GAP $=$ RSA-RSL. When RSA $=$ RSL, GAP $=0$, and we call banks are at zero interest rate risk. The net profit margin of banks remains unchanged regardless of whether the interest rate rises or decreases. When RSA $>$ RSL, GAP $>0$. The rise of interest rate will make the bank profit, and vice versa. When RSA $<$ RSL, GAP $<0$. When the interest rate rises, the bank is damaged, and vice versa.

\section{B. Analysis of duration gap}

Duration is a time-weighted average value, which is a great reflection of the average time spent in each phase of the investment to make up for the initial investment. Duration gap is estimated as follows:

$$
D_{\text {Gap }}=D A-\mu D L
$$

where, DA is the duration of total assets; DL represents the duration of total liabilities; and $\mu$ stands for the asset-liability ratio and is calculated by market value.

For fixed-income securities, the change of interest rates is opposite to the change of their prices. The impact of interest rate changes on the net market value of banks is shown in TABLE I below:

TABLE I. THE EFFECT OF INTEREST RATE CHANGES ON NET MARKET VALUE

\begin{tabular}{|c|c|c|c|c|c|}
\hline $\begin{array}{c}\text { Duration } \\
\text { Gap }\end{array}$ & $\begin{array}{c}\text { Change } \\
\text { of interest } \\
\text { rates }\end{array}$ & $\begin{array}{c}\text { Change } \\
\text { of market } \\
\text { value of } \\
\text { assets }\end{array}$ & $\begin{array}{c}\text { Changing } \\
\text { size }\end{array}$ & $\begin{array}{c}\text { Change } \\
\text { of market } \\
\text { value of } \\
\text { liabilities }\end{array}$ & $\begin{array}{c}\text { Change of } \\
\text { the net } \\
\text { market } \\
\text { value }\end{array}$ \\
\hline Positive & Increase & Decrease & $>$ & Decrease & Decrease \\
\hline Positive & Decrease & Increase & $>$ & Increase & Increase \\
\hline Zero & Increase & Decrease & $=$ & Decrease & Unchanged \\
\hline Zero & Decrease & Increase & $=$ & Increase & Unchanged \\
\hline Negative & Increase & Decrease & $<$ & Decrease & Increase \\
\hline Negative & Decrease & Increase & $<$ & Increase & Decrease \\
\hline
\end{tabular}

\section{VaR model}

In recent years, VaR model has been favored in interest rate risk management. Compared with traditional risk measurement methods, VaR model gives the level of interest rate risk after big data processing, and describes the maximum of trading losses in the particular time and confidence level. Therefore, $\mathrm{VaR}$ is a function of two variables: time outlook (T) and confidence (X \%). The selection of these two important parameters depends on the purpose of the user.

\section{EMPIRICAL ANALYSIS OF INTEREST RATE RISKS IN CHINA}

In this part, GAP model and GARCH model are used comprehensively to carry on the empirical analysis. Based on the annual report and SHIBOR overnight interest rates data, the interest rate risk and management level are studied from micro and macro aspects.

\section{A. GAP model analysis -- Taking Bank of China (BOC) as an example}

Bank of China (BOC), one of the four biggest commercial banks in China, is operating continuously more than one hundred years, which means that it is representative of Chinese commercial banks. Data of BOC's annual report in 2016 are selected. 
TABLE II. ANALYSIS OF INTEREST RATE SENSITIVE GAP OF BANK OF CHINA (UNIT: MILLION)

\begin{tabular}{|c|c|c|c|c|c|c|c|}
\hline & $<1$ month & $1 \sim 3$ months & 3 months 1 year & $1 \sim 5$ years & $>5$ years & Non-interest bearing & Total \\
\hline RSA & 4286155.00 & 2412227.00 & 5286969.00 & 1760598.00 & 1023495.00 & 1218541.00 & 15987985.00 \\
\hline RSL & 7778486.00 & 1461571.00 & 2960246.00 & 1855027.00 & 56943.00 & 596702.00 & 14708975.00 \\
\hline GAP & -3492331.00 & 950656.00 & 2326723.00 & -94429.00 & 966552.00 & 621839.00 & 1279010.00 \\
\hline SR & 0.55 & 2.54 & 2.27 & 0.95 & 17.97 & 2.04 & 1.09 \\
\hline Interest rate+1\% & -34923.31 & 9506.56 & 23267.23 & -944.29 & 9665.52 & 0.00 & 12790.10 \\
\hline Interest rate-1\% & 34923.31 & -9506.56 & -23267.23 & 944.29 & -9665.52 & 0.00 & -12790.10 \\
\hline
\end{tabular}

Overall, there is a slight increase in the GAP value of Bank of China (BOC). According to the definition of duration gap, higher the value, higher the risk. Because the forecast of shortterm interest rate is further more credible, Bank of China takes the initiative to respond to the risk for a short time in the future, which is presented as the large gap within 3 months. Meanwhile, due to the unpredictable forward interest rate, long-term GAP value is relatively small, which shows that BOC adopts a more conservative management strategy in the long run.

\section{B. GARCH model analysis}

All available overnight lending rates $(\mathrm{O} / \mathrm{N})$ from Jan 4, 2010 to Dec 30, 2016 are collected for use (1,748 sample points), and the confidence level is set to $95 \%$ here.

\section{TABLE III. ADF TEST RESULTS}

\begin{tabular}{|c|c|c|c|}
\hline \multicolumn{2}{|c|}{} & t-Statistic & Prob. \\
\hline \multicolumn{2}{|c|}{ Augmented Dickey-fuller test statistic } & -37.7690 & 0.0000 \\
\hline \multirow{2}{*}{ Test critical values } & $1 \%$ & -3.433892 & 0.0000 \\
\cline { 2 - 4 } & $5 \%$ & -2.862991 & 0.0000 \\
\cline { 2 - 4 } & $10 \%$ & -2.567590 & 0.0000 \\
\hline
\end{tabular}

Regression analysis of non-stationary time series may result in false regression. In order to obtain a stable time series, the original data are processed by means of logarithmic redifference. The results in TABLE III show that $t$ values are tested at three significant levels, which indicates that the sequence has no unit root. In other words, the sequence after processing is stable.

Due to the influence of inertia of economic behaviors and other factors, financial time series usually have a certain degree of self-correlation, which will greatly influence the estimation results of the model. Therefore, it is necessary to conduct correlation test on the data after processing. According to the output of EViews8.0, autocorrelation and partial autocorrelation values are not zero. With the probability closed to $0, \mathrm{P}$ value is far less than $5 \%$, so the original sequence processed by means of logarithmic redifference can be thought of an autocorrelation sequence and the regression model can be used.

According to the above data, this paper selects GARCH (1, 1) model to study the risk value. The standard $\operatorname{GARCH}(1,1)$ model consists of two equations, which can be expressed as follows:

$$
\begin{gathered}
y_{t}=\beta X_{t}+\mu_{t} \\
\sigma_{t}^{2}=\alpha_{0}+\alpha_{1} \mu_{t-1}^{2}+\alpha_{2} \sigma_{t-1}^{2}
\end{gathered}
$$

where, $\mu_{t}$ is white noise; $\sigma_{t}^{2}$ is the issue of fitting variance at time t. Combining with sample data, the conditional mean equation is established:

$$
\ln \left(p_{t}\right)=C(1)+C(2) \ln \left(p_{t-1}\right)+\mu_{t}
$$

Estimating the parameters, results are shown in Table IV. The conditional mean equation and the conditional variance equation are given by:

$$
\begin{gathered}
\ln \left(p_{t}\right)=0.006665+0.991815 \ln \left(p_{t-1}\right) \\
\sigma_{t}^{2}=0.000066+0.413029 \mu_{t-1}^{2}+0.719215 \sigma_{t-1}^{2}
\end{gathered}
$$

The ARCH effect is tested by LM test for the residual sequence after the model is established, and the probability value of F-Statistic is greater than 0.05 , which means no $\mathrm{ARCH}$ effect exists. And it is manifest that the model fits the time series of logarithmic yield very well, so the model can be used to predict the overall interest rate risk faced by commercial banks if the financial environment does not change a lot.

TABLE IV. ESTIMATION RESULTS OF GARCH MODEL

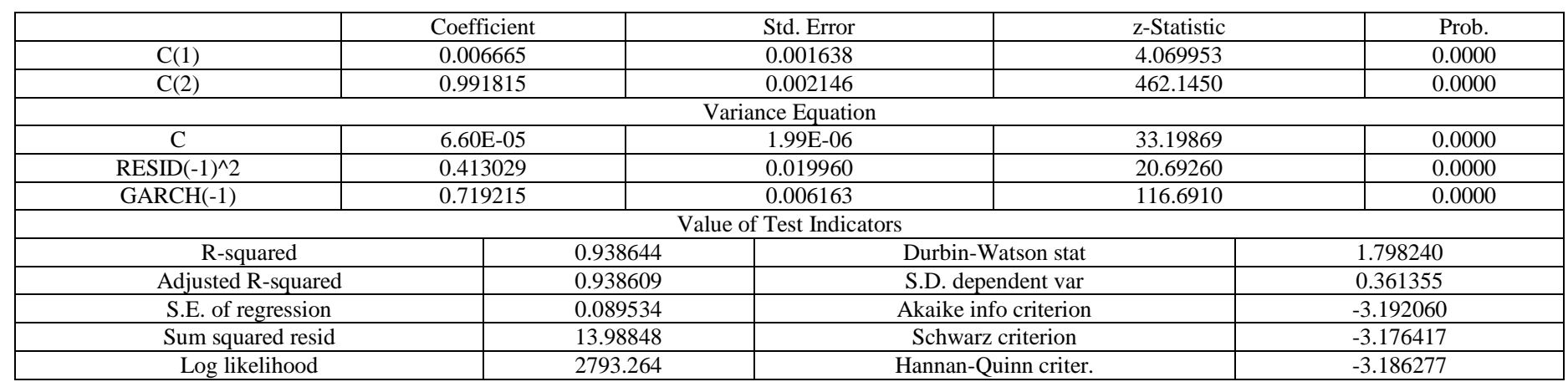




\section{CONCLUSION}

It can be seen easily from the above model that the absolute value of $\mathrm{C}(1)$ is very small, so the parameter estimation of the mean equation is consistent with requirements because generally speaking, the mean of yield is close to zero. In addition, the constant term of the mean variance is greater than zero, so it can be considered that the interest rate will fluctuate severely under the influence of various external factors. Finally, the estimated value of the coefficient of $\sigma_{t-1}^{2}$ is 0.719215 , indicating that the yield sequence has the characteristic of longterm memory.

\section{REASONABLE SUGgestions For COMMERCIAL BANKS}

Firstly, strengthen the monitoring and quantitative analysis of risks, especially the interest rate risk. Commercial banks should establish econometric models for the interest rate prediction, and give full consideration to the various influencing factors. With the help of computer technology, banks can also estimate interest rate risks and make management decisions easily when multiple interest rates change.

Exploring new ideas for pricing financial products is another effective way to mitigate risks. Banks are enterprises that manage money assets, and the price of products is their core business. Interest rate liberalization gives commercial banks greater rights in the pricing of deposit and lending rates. Commercial banks should rapidly strengthen their understanding of interest rate risks and set their own pricing methods.

Change the management mode of assets and liabilities. It is obvious that the management of interest rate risk is becoming the top priority in the management of the assets and liabilities of commercial banks in the future. Banks should make adjustments to the asset and liability management plan, improve the accuracy of the analysis and forecast, and optimize the structure of the internal and external projects.

In addition, the intermediary business should be developed vigorously. At present, Chinese commercial banks are mainly engaged in intermediary business such as agent settlement, which has low added value and limited profitability. Intermediary business in our country still has a large excavation space. Commercial banks should take advantage of their own widespread branches and information advantages to develop and expand such businesses.

Besides, financial innovation should not be neglected. Commercial banks can avoid the negative effects of interest rate liberalization through some financial innovations. Recently, Chinese commercial banks have had the consciousness of financial products innovation despite the most dependent heavily on the interest spreads. So they should put much more efforts into research and innovation inevitably for their longterm development.
During the process of interest rate liberalization, commercial banks will inevitably face various risks. This paper first puts forward the definition of interest rate liberalization and interest rate risk and the classification of interest rate risk, and then introduces three available methods to measure the risk of interest rate. Then, the GAP model and GARCH model are used to analyze the recent data of China. Empirical study shows that commercial banks in China have actively managed short-term GAP values in face of interest rate risks. Meanwhile, the yield sequence has the characteristic of long-term memory.

Every coin has two sides. When commercial banks suffer a risk of loss, it also means a great opportunity for them to achieve better development, which commercial banks in China should make great efforts to take advantage of. Strengthening the monitoring and quantitative analysis of risks, exploring new ideas for pricing financial products, changing the management mode of assets and liabilities, developing the intermediary business vigorously, and concentrating on financial innovation are all what commercial banks should do urgently.

\section{ACKNOWLEDGMENT}

This paper is supported by College Students' Innovation and Entrepreneurship Training Program of Jiangsu Province, China (No. 201710327037Y).

\section{REFERENCES}

[1] Dan Armeanu, Florentina-Olivia Balu, Carmen Obrej. Interest Rate Risk Management Using Duration Gap Methodology [J]. Theoretical and Applied Economics, 2008, 01(518).

[2] Delis, Manthos D. \& Kouretas Georgios P. Interest Rates and Bank Risk-taking [J]. Journal of Banking \& Finance, Elsevier, vol.35 (4), pages 840-855, April, 2011.

[3] Edwards Shaw. Financial Deepening in Economic Development [M]. New York: Oxford University Press, 1973.

[4] Huang Jinlao. Interest Rate Liberalization and Risk Control of Commercial Banks [J]. Economic Research, 2001, (01):19-28+94.

[5] Jiang Wen. Analysis on the Development Strategies of Commercial Banks in Small and Medium-sized Cities Under Interest Rate Liberalization -- Taking Bank A as an Example [J]. Times Finance, 2016, (18):78-79.

[6] Li Hongjin. The Challenge and Response of Interest Rate Liberalization to Commercial Banks [J]. International Financial Research, 2015, (02):65-76.

[7] Lv Yaoming, Lin Sheng. Research on Interest Risk Management of Commercial Banks [J]. Economic Research, 1999, (05):28-33.

[8] Ronaldl Mckinnon. Money and Capital in Economic Development [M]. Brookings Institution Press, 1973.

[9] Shao Fujun. Risk Analysis of Interest Rate Liberalization [J]. Financial Research, 2004, (06):90-103.

[10] Tressel. A New Database of Financial Reforms [R]. IMF Woring Paper, 2009. 